\title{
A Three-Phase Multiobjective Mechanism for Selecting Retail Stores to Close
}

\author{
Rong-Chang Chen and Shu-Ping Suen \\ Department of Distribution Management, National Taichung University of Science and Technology, No. 129, Sec. 3, Sanmin Road, \\ Taichung 404, Taiwan
}

Correspondence should be addressed to Rong-Chang Chen; rcchens@nutc.edu.tw

Received 9 January 2016; Revised 3 April 2016; Accepted 26 April 2016

Academic Editor: Juan C. Leyva

Copyright (C) 2016 R.-C. Chen and S.-P. Suen. This is an open access article distributed under the Creative Commons Attribution License, which permits unrestricted use, distribution, and reproduction in any medium, provided the original work is properly cited.

\begin{abstract}
To operate a successful and growing business, a retail store manager has to make tough decisions about selectively closing underperforming stores. In this paper, we propose using a three-phase multiobjective mechanism to help retail industry practitioners determine which stores to close. In the first phase, a geographic information system (GIS) and $k$-means clustering algorithm are used to divide all the stores into clusters. In the second phase, stores can be strategically selected according to the requirements of the company and the attributes of the stores. In the third phase, a neighborhood-based multiobjective genetic algorithm (NBMOGA) is utilized to determine which stores to close. To examine the effectiveness of the proposed three-phase mechanism, a variety of experiments are performed, based partly on a real dataset from a stock-list company in Taiwan. Results from the experiments show that the proposed three-phase mechanism can help efficiently decide which store locations to close. In addition, the neighborhood radius has a considerable influence on the results.
\end{abstract}

\section{Introduction}

Retail is one of the largest industries in the world [1,2]. While there is still room for the retail industry to expand, retail store operators are facing some intense pressure [3]. The pressure is straightforward. As more and more competitors enter this industry, the operating profit is considerably shrunk and, thus, some operators have to close some underperforming stores and/or withdraw from the industry $[3,4]$.

To close retail stores, some important factors must be considered. The first important factor is profit. In order to ensure that the company can make a profit, the manager has to close some underachieving stores that no longer meet the company's requirements. The second critical factor to be considered is the distance customers need to drive or walk to get to a store. One of the most important factors affecting customer store choice is the travelling time [5]. If the distance is too long, the customer may choose alternatives from other brands. The third factor to be considered is the percentage of the company's employees who quit as a result of store closures. Employees have to change their work locations once a store is closed. Many of the employees are part-time students, who tend to find jobs near their schools. If the distance from the new work location to the school is too far, they are very likely to quit the job, which will waste a huge amount of training costs and cause instability in store operations. Thus, to reduce employee turnover rate, the closure decision should shorten the possible movement distance as much as possible. Another influencing factor is concerned with the strategy of the firm [6]. Some stores are strategically retained even if their profits are low. These stores may include, for instance, a store used for training or historical or symbolic store for the firm.

For several decades, one selection problem concerning retail stores has been focusing on selecting suitable store locations to open [7-15]. To the best of our knowledge, little literature presents any mechanism to decide which stores to close or discusses the effects of closing on the retailer's performance [16-18]. To help managers solve the problem mentioned above, this study presents a novel mechanism which consists of three phases. In the first phase, retail stores are grouped based on their geographic distribution. In the second phase, strategically desirable stores are selected and they are kept 


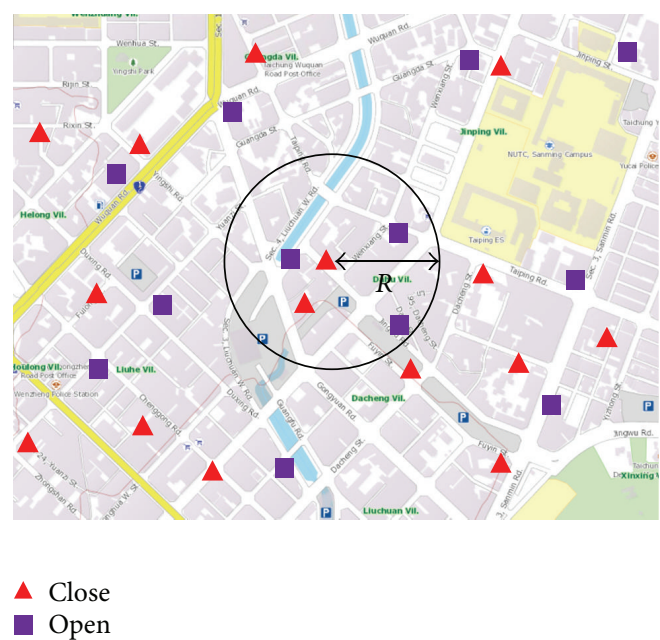

FIGURE 1: Nearby stores of a selected (to-close) store.

open. The goal of the third phase is to optimally determine which of the remaining stores in the second phase to close.

The remainder of this paper is organized as follows. In Section 2, a brief description of the store selection problem as well as modeling is presented. In Section 3, the proposed mechanism is introduced. Results and discussion are presented in Section 4. In Section 5, conclusions are drawn.

\section{The Store Selection Problem}

In this section, we start with a brief description and a presentation of the mathematical formulation for the problem.

For ease of description, some variables are first defined. Let $S=\left\{x_{i} \mid i=1, \ldots, s_{0}\right\}$ be a set of retail stores, where $s_{0}$ is the total number of stores a firm possesses. Suppose that a percentage of stores have to keep open. The percentage is designated as $p$ and $0 \leq p<1$. For example, if $p$ is $90 \%$, then $10 \%$ of stores are to close. For $i=1, \ldots, s_{0}$, we let $x_{i}=0$ if store $i$ is selected to close. Otherwise, $x_{i}$ is set to be 1 . To save space, if a store is selected to close, we call it a selected store; otherwise, the store is kept open. Some employees working at the selected stores have to change their working places and they have to move a distance from the original store to the new one. Similarly, customers have to travel a distance if a store nearer to them is closed. The farther the movement distance is, the more likely it would be for an employee to quit the job or for a customer to select alternatives from other brands. To evaluate the total movement distance of store $i$ caused by closure, we define nearby stores of a selected store $i$ (as the center) as those stores which are located within a circle region with a radius $R$, as shown in Figure 1 . Since several stores may exist within the neighborhood of store $i$, we designate $N_{i j}$ as the $j$ th nearby store of store $i$. If the $j$ th nearby store of store $i$ is a selected one, $N_{i j}=0$; otherwise, $N_{i j}=1$. The total number of nearby stores for store $i$ is $n_{i}$.

There are two objectives for store closure decisions. The first objective is to minimize the total profit loss, which is defined as the profit difference before and after closure. Note that the loss is based on profit rather than revenue.
An increase in revenue may cause a loss in profit because of an increased cost. Consequently, a profit-based objective is a more feasible one for closure decisions. On the other hand, to decrease sales loss caused by lost customers and to reduce the rate at which employees quit their jobs, the total distance from the selected store to its nearby stores is minimized. The mathematical formulation of this problem can thus be given by the following.

Objectives are

$$
\begin{array}{ll}
\text { Minimize } & Z_{1}=\sum_{i=1}^{s_{0}}\left(V_{i}-C_{i}\right)\left(1-x_{i}\right) \\
\text { Minimize } & Z_{2}=\sum_{i=1}^{s_{0}} \sum_{j=1}^{n_{i}}\left(1-x_{i}\right) d_{i j}\left(1-N_{i j}\right),
\end{array}
$$

subject to

$$
\begin{aligned}
\sum_{i=1}^{s_{0}} x_{i} & = \begin{cases}s_{0} p & \text { if } s_{0} p \text { is an integer, } \\
\operatorname{Int}\left(s_{0} p\right)+1 & \text { otherwise, }\end{cases} \\
\sum_{j=1}^{n_{i}} N_{i j} & \geq 1 \quad i=1, \ldots, s_{0}, \\
x_{i} & \in\{0,1\} \quad i=1, \ldots, s_{0},
\end{aligned}
$$

where $V_{i}$ is the revenue of store $i, C_{i}$ is the cost of store $i, d_{i j}$ is the distance from store $i$ to its $j$ th nearby store, and

$$
x_{i}= \begin{cases}0 & \text { if store } i \text { is selected to close } \\ 1 & \text { otherwise }\end{cases}
$$

Equation (2) states that the total number of stores selected to open is equal to a specific number, which is equal to $s_{0} p$ if $s_{0} p$ is an integer, or the number is equal to $\operatorname{Int}\left(s_{0} p\right)+1$ if $s_{0} p$ is not an integer. Equation (3) requires that at least one of the nearby stores of a selected store $i$ remains open, ensuring that the customers can find at least an alternative open store within a distance $R$.

\section{Three-Phase Mechanism}

3.1. The Decision Framework. There are three basic phases for solving the selection problem, which we illustrate in Figure 2 and then discuss in more detail. In each phase, there are some influencing factors.

Phase I: Clustering Stores. When the number of stores involved is large, it is reasonable for an operator to divide all the retail stores into several clusters, based on the objectives of the company. For example, Seven-Eleven Japan builds a cluster of around 50 to 60 stores supported by a distribution center. Such clustering allows Seven-Eleven Japan to operate an efficient system [20]. One commonly used clustering scheme is based on location. Stores located in close proximity to each other are aggregated, using a geographic information system (GIS) [21, 22] or other clustering techniques [23]. 


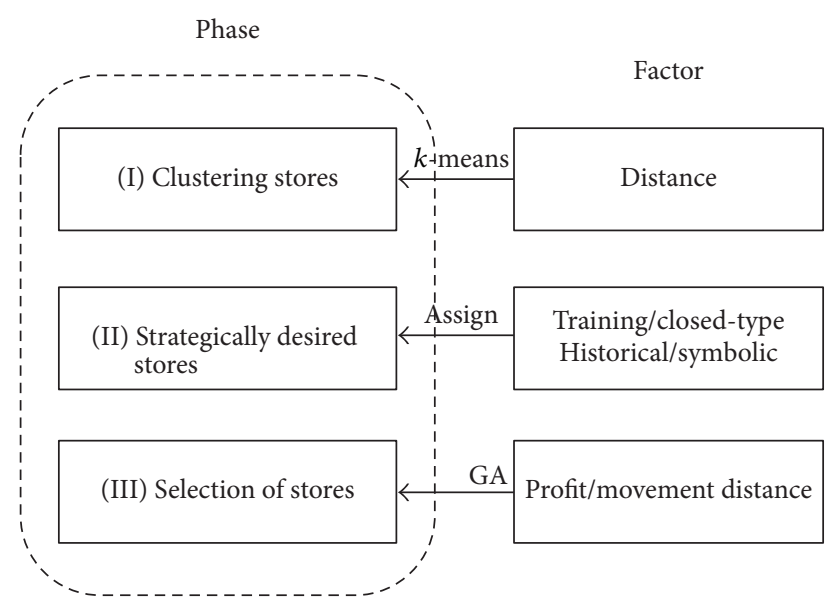

FIgURE 2: A three-phase decision framework.

TABLE 1: The values of $x_{i}$ for the six stores in the example. For reasons for open/close decisions, please refer to Phase II, Section 3.1.

\begin{tabular}{lcccccc}
\hline Store & $1(i=1)$ & $2(i=2)$ & $3(i=3)$ & $4(i=4)$ & $5(i=5)$ & $6(i=6)$ \\
\hline Reason & $(3)$ & $(1)$ & $(4)$ & $(4)$ & $(2)$ & $(3)$ \\
$x_{i}$ & 1 & 1 & 1 & 0 & 1 & 1 \\
\hline
\end{tabular}

Among the popular clustering algorithms, $k$-means $[24,25]$ is one of the simplest techniques.

Phase II: Strategically Desired Stores. In this phase, some stores are strategically kept. This phase aims to achieve the strategic objectives of the firm. An additional benefit of this phase is the reduction in the amount of computational time. The higher the number of stores, the more the computational time needed.

The possible reasons for strategic stores may include the following:

(1) Stores for training: personnel at all levels should be trained to meet the firm's needs to provide products and services of a required quality. Therefore, some stores used for training should be kept.

(2) Closed-type stores: this kind of store is located in a closed area, such as a campus or a military camp. The stores generally are not open to the public.

(3) Historic or symbolic stores: for instance, the first retail store opened in an area or a symbolic store at a famous tourist attraction will be retained.

(4) Others: this point refers to those stores subject to very strict contracts or local regulations [26].

Phase III: Selection of Stores. In this phase, optimization of store selection is achieved based on the company's objectives. The most important objective for many companies is profit. They tend to minimize the total profit deficit. Another important consideration is distance. A shorter movement distance caused by closing stores can reduce the turnover rate of employees. In addition, the customer can drive or walk to a store with a shorter distance.
In this paper, we use a genetic algorithm, which has been successfully applied to many fields [19, 27-34], to optimize store selection. The detail is depicted in the following subsection.

\subsection{Method of Solution}

3.2.1. Using k-Means Algorithm for Clustering in Phase I. $k$ means is one of the most popular clustering algorithms, in which items are moved among sets of clusters until the desired set is reached [25]. $k$-means is most suited for separating convex clusters $[35,36]$. An additional advantage of using $k$-means algorithm is that we can use its centroid in a cluster as the location of the distribution center. To cluster stores using $k$-means, the input data, including the number of clusters $k$, the location coordinates of stores, and the convergence criterion, should be given. The value of $k$ depends on the needs of the manager. Generally, $k$ varies from three to six. In this paper, the algorithm is organized as follows:

Input:

$k$ //Number of desired clusters

$D=\left\{\left(x_{1}, y_{1}\right),\left(x_{2}, y_{2}\right),\left(x_{3}, y_{3}\right), \ldots,\left(x_{n}, y_{n}\right)\right\}$ //Set of store points

Output:

$K / /$ Set of clusters

$k$-means algorithm:

Assign initial values for means; $m_{1}, m_{2}, \ldots, m_{k}$ Repeat

Assign each item $\left(x_{i}, y_{i}\right)$ to the cluster which has the closest mean;

Calculate new mean for each cluster;

Until convergence criteria are met (All the values between two iterations are the same).

3.2.2. Deciding Strategically Desired Stores in Phase II. Some stores can be selected to remain open or to close before going to the third phase, in order to reduce computation time. For easy understanding, examples are given as follows. Suppose that a store chain has six stores to be strategically kept open or closed, as shown in Table 1. The scenarios are as below.

Store 1. This store is the first one to be opened for the store chain. This store is chosen to keep open. Thus, the decision variable $x_{1}$ is set to be 1 , as shown in Table 1 .

Store 2. The store is established mainly for training. This store will not be closed even if profit is low. Consequently, $x_{2}$ is set to be 1 .

Store 3. This store is subjected to a strict contract. Even if the store is closed, the store owner has to pay rent. As a result, store 3 will be open in the next period. 


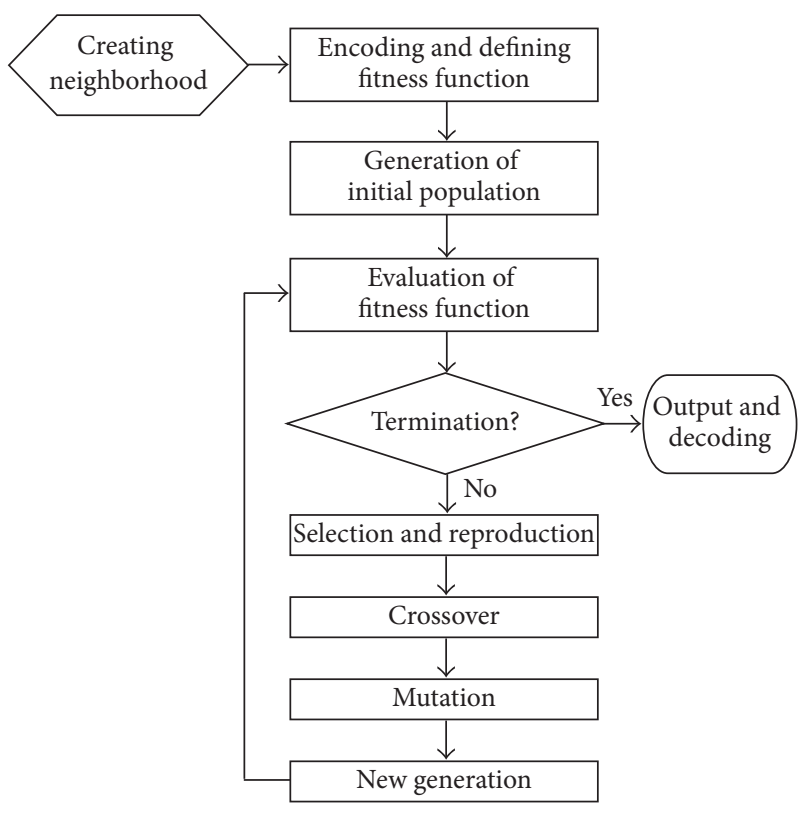

FIgURE 3: The flowchart for the genetic algorithm.

$\begin{array}{llllllllllllllll}\text { Store number } & 1 & 2 & 3 & 4 & 5 & 6 & 7 & 8 & 9 & 10 & 11 & 12 & 13 & \cdots & s_{n}\end{array}$ \begin{tabular}{l|l|l|l|l|l|l|l|l|l|l|l|l|l|l|l|}
\hline Close or not & 0 & 1 & 0 & 0 & 1 & 0 & 0 & 0 & 1 & 0 & 0 & 1 & 0 & $\cdots$ & 0 \\
\cline { 2 - 10 }
\end{tabular}

FIGURE 4: Representation of a chromosome.

Store 4. The lease term of the store is ended and the store owner wants to terminate the lease. The store is forced to close. Therefore, $x_{4}=0$.

Store 5. This store is located within an important military region. The store is established for the sake of service and will always be kept open. Therefore, $x_{5}=1$.

Store 6. This store is located in a famous tourism region. It is chosen to remain open, no matter what the level of profit is.

A summary of the values of decision variable $x_{i}$ for these six stores is shown in Table 1.

\subsubsection{Using Genetic Algorithm to Optimally Select Closing} Stores in Phase III. A neighborhood-based multiobjective genetic algorithm (NBMOGA) is developed to solve the selection problem. The flowchart for the GA is illustrated in Figure 3 and the details are described in the following subsections.

(1) Encoding and Initial Population. A binary encoding is employed, as shown in Figure 4. The sequence number stands for the store number. Since the number of stores is $s_{n}$ after strategic selection for the $n$th cluster, there are $s_{n}$ genes in a chromosome. The value in the gene is either 1 or 0 , where 0 means the store is selected to close and 1 means the store is to be kept open.

A random method is employed to generate the initial population.
(2) Evaluation of Fitness Function. The chromosomes are evaluated based on the total profit deficit and the total movement distance. Nondominated fitness values are recorded and their corresponding solutions are chosen as the Pareto ones. In this paper, the scheme utilized to find Pareto solutions is a rank-based approach [19]. Suppose that an individual $G_{h}$ at generation $t$ is dominated by $q_{h}^{(t)}$ individuals in the present generation. Then, the rank of the individual at generation $t$ can be expressed as [33]

$$
\operatorname{rank}\left(G_{h}, t\right)=1+q_{h}^{(t)}
$$

All the nondominated individuals are assigned rank 1 , as illustrated in Figure 5. Take chromosome A as an example. Its fitness value is $\left(X_{\mathrm{A}}, Y_{\mathrm{A}}\right)$. If no other chromosomes exist within the rectangular regions $0 \leq Z_{1} \leq X_{\mathrm{A}}$ and $0 \leq Z_{2} \leq$ $Y_{\mathrm{A}}$, the rank of the chromosome is assigned as 1. Likewise, the rank of chromosome B is 1 , since no chromosomes are within the regions $0 \leq Z_{1} \leq X_{\mathrm{B}}$ and $0 \leq Z_{2} \leq Y_{\mathrm{B}}$. All the chromosomes ranked as 1 are collected into the Pareto set. The Pareto set is updated at each generation. As evolution continues, the Pareto set will gradually shift toward exploiting the nondominated points in the criteria space. The process is continued until the end condition is reached.

(3) Selection. The binary tournament selection method [28] is employed to select the fitter individuals. Tournament selection is similar to rank selection in terms of selection pressure, but it is computationally more efficient and more amenable to parallel implementation [28]. The process is as follows. First, two chromosomes are randomly chosen from the population. The fitter one is selected to become parent $\mathrm{A}$ and the process is repeated to select another parent B. Subsequently, the GA combines parents A and B to generate the offspring.

(4) Crossover. The uniform crossover method is employed to generate offspring. The method is to generate a mask, which has a length equal to the chromosome and is composed of a random set of binary numbers. Figure 6 illustrates the uniform crossover scheme. Where there is a "1" in the mask, the value of a gene is copied from parent $\mathrm{A}$; otherwise, the gene is copied from parent $\mathrm{B}$. The offspring contain a mixture of genes from each parent. For example, the value of the first cell in the mask is "0," indicating that the value of the first gene for the offspring is copied from parent $\mathrm{B}$. Therefore, the value assigned will be "1." The procedure is continued until all of the values of the genes are copied.

(5) Mutation. Three genes in the chromosome are randomly selected and their values are changed, as illustrated in Figure 7. The advantage of using three-gene mutation is that it increases the diversity of chromosomes and then increases the possibility of finding optimal solutions.

(6) Adjustment. Since the percentage of open stores is required to be equal to the preassigned value $p$, some of the gene values should be adjusted if the percentage is different from the required value. The GA program will check the percentage after genetic operations. If the actual percentage 

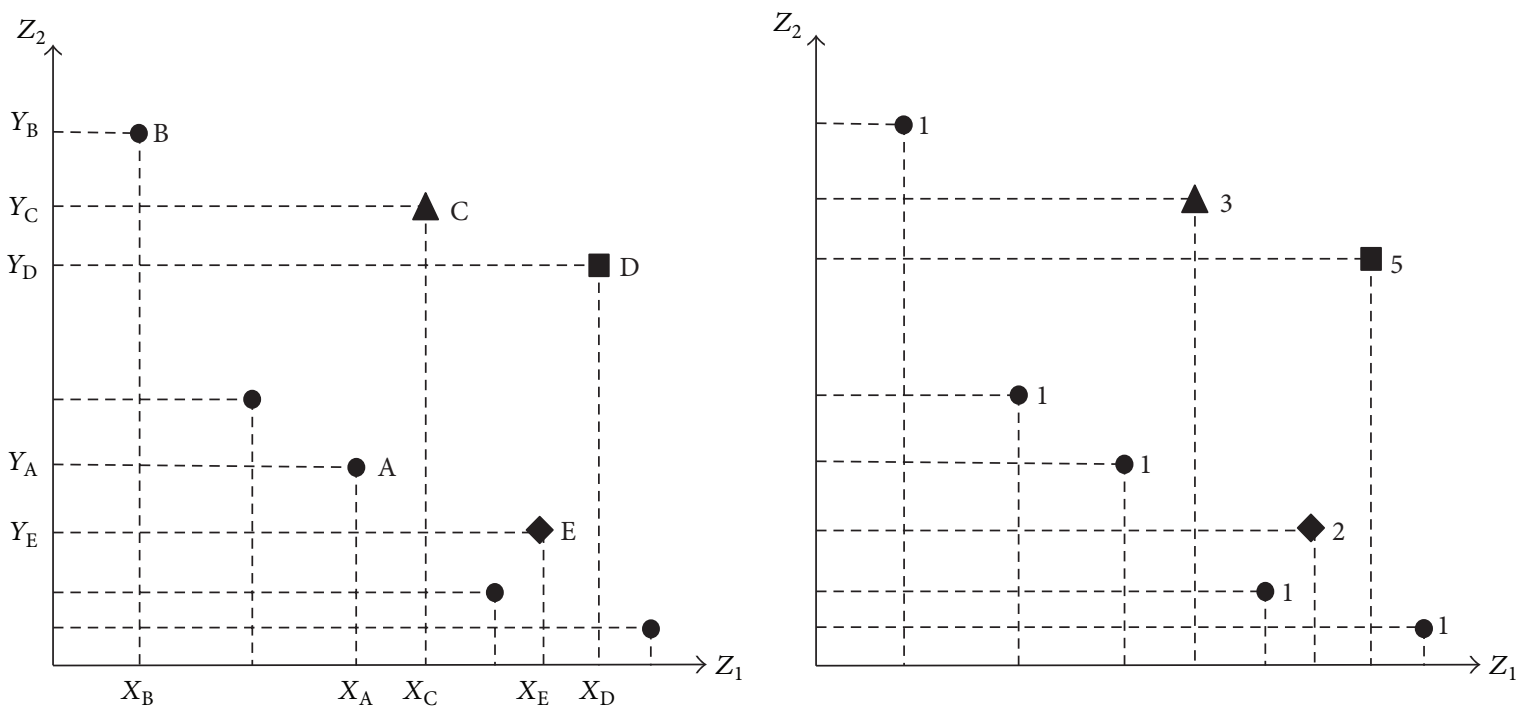

FIgURE 5: The ranking in the present scheme. All the nondominated individuals are assigned rank 1 [19].

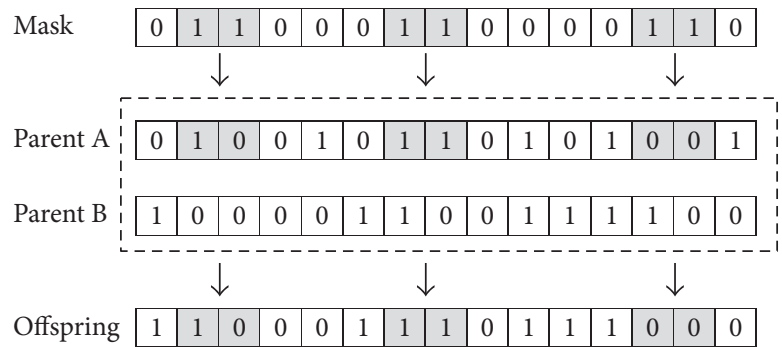

FIGURE 6: Illustration of uniform crossover.

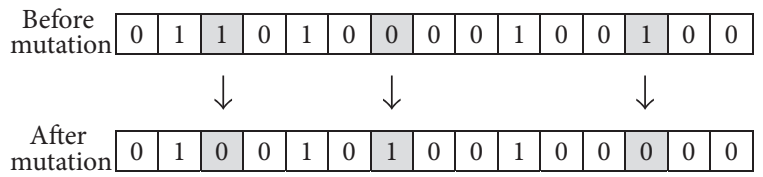

FIGURE 7: Illustration of a three-point mutation method.

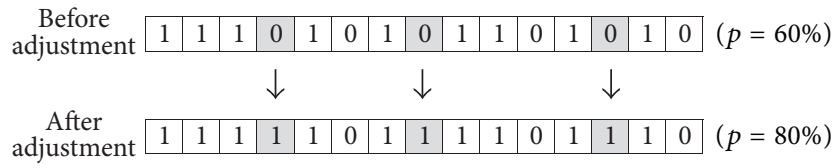

FIGURE 8: Illustration of adjustment.

exceeds $p$, some of the unselected stores will become selected, while some of the selected stores will become unselected, if the actual percentage is smaller than $p$. The process is repeated until the percentage of selected stores is equal to $p$, as shown in Figure 8.

(7) Replacement. The tournament selection method is used to replace the worst chromosomes. First, chromosome A is randomly chosen from the population of the previous generation. Then, the chromosomes in the next generation are

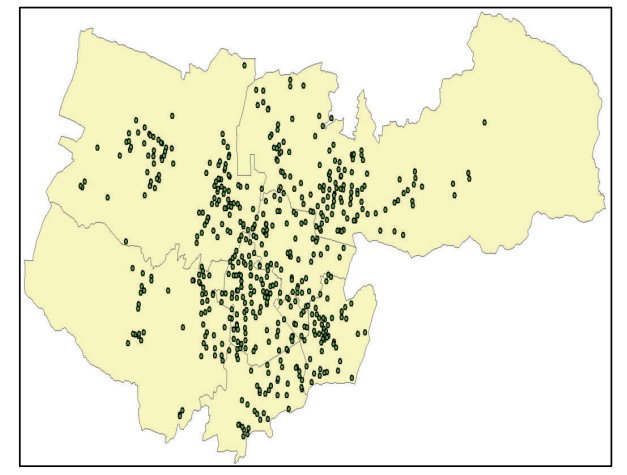

FIgURE 9: The distribution of retail stores.

compared with chromosome A. If there is any chromosome better than chromosome $\mathrm{A}$, the replacement is done. The process is repeated until all the chromosomes in the next generation are compared.

(8) Termination. The program is run until a preassigned generation number is reached.

\section{Results and Discussion}

To evaluate the effectiveness of the proposed approach, a variety of experiments were performed using a reference case. Part of the dataset is from a famous chain store sector in Taichung City, Taiwan. The reference case includes 550 stores. The distribution is depicted in Figure 9. The neighborhood radius is set to $1 \mathrm{~km}$ and the generation number is set to be 50,000 at the reference case.

The GA program used in this study was coded with Visual Studio $\mathrm{C}++$. The program was run on an Intel(R)Core(TM)i7-2600 CPU @ 3.40 GHz with a $4.00 \mathrm{~GB}$ RAM. The operating system is Windows 7. 


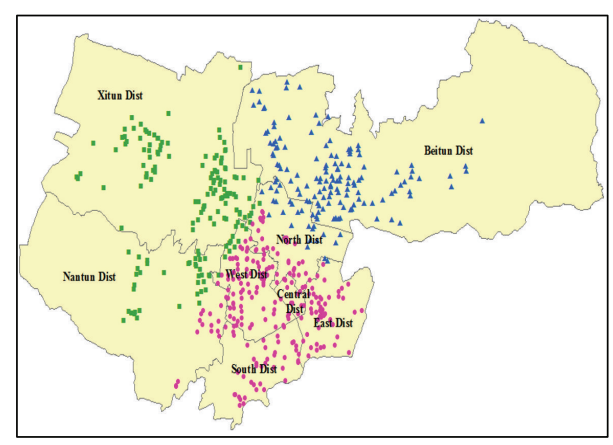

(a)

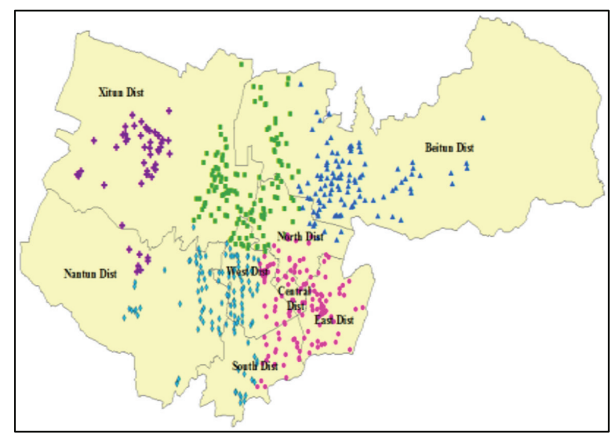

(c)

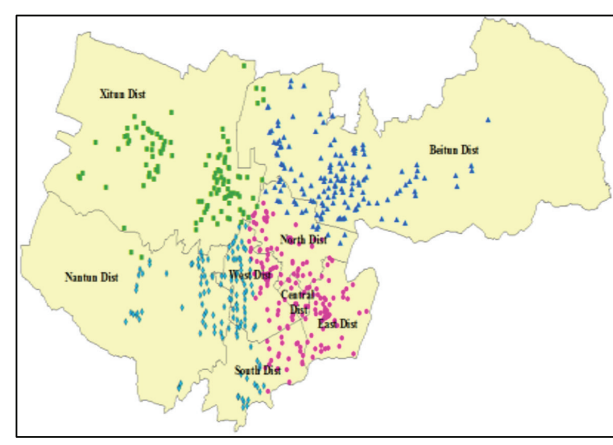

(b)

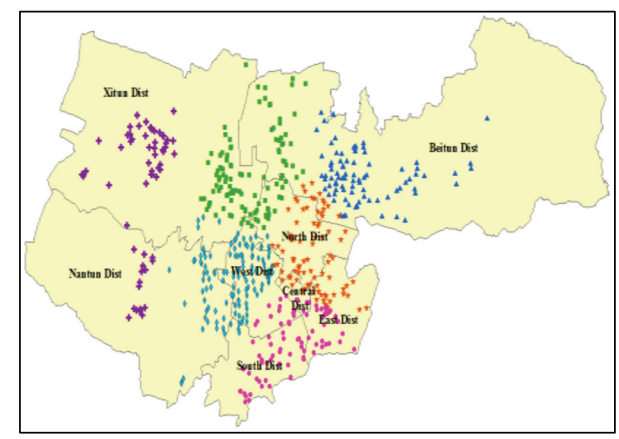

(d)

FIGURE 10: (a) The results of clustering with $k=3$. (b) The results of clustering with $k=4$. (c) The results of clustering with $k=5$. (d) The results of clustering with $k=6$.

4.1. The Clustering Result. The stores were clustered using $k$-means algorithm $[24,25]$. The number of clusters $k$ varied from three to six. The clustering results are shown in Figure 10. In the region with lower store density, the stores are easier to cluster. However, when store density is higher, it is difficult to divide the stores in an intuitional way and, thus, an efficient tool is needed. Results from this study show that the clustering tool developed by this study can efficiently cluster stores. Combined with GIS, the clustering results are easily observed and facilitate decision-making by the manager.

4.2. The Results of Store Selection. In this paper, we use GA (NBMOGA) to optimize store selection. At the reference case, $k$ was set to be 4 . Each case was run ten times and the best results are kept and compared. The GA parameters, including generation number, mutation rate, crossover rate, and population number, were tested. A variety of experiments show that the generation number $=50,000$, the mutation rate $=0.05$, the crossover rate $=0.9$, and the population number $=$ 30 can obtain stable solutions.

In this paper, a rank-based scheme is employed to find Pareto solutions. We have used this scheme to solve some multiobjective problems and the results from GA are compared well with an exact algorithm $[19,31]$. The results from the two previous studies $[19,31]$ show that the GA scheme we used in this study has good performance when it is compared with the Brutal-Force Method (BFM).

The optimized results are shown in Figures 11(a)-11(d). The points marked by green color (triangle) are stores selected to close, while those marked by red color (square) are to remain open. Since the retail network is so complex, it is very difficult to select stores for shuttering by simple rules only. Though the network is quite complex, the system developed in this paper is rather easy to use and can help the manager in efficient simulation. It requires only seconds to find solutions, even when the number of stores is as high as 550 . One clear advantage of the genetic algorithm is that, by its very nature, we are able to produce a number of feasible solutions, thus facilitating discussion on the merits of various decisions and supporting multiobjective decision-making [34].

The interrelationship between stores is complex. For example, if a store is strategically retained to be open, what will its influence be on the other stores? To facilitate this issue, the GA program is designed to be easy to use. As shown on the left side of Figure 12, if a store is selected to be strategically retained, just by setting the value of the attribute in the input data to be " 1 ," then the store will be retained by the program (see the output result on the right side of Figure 12).

4.3. The Influence of Opening Percentage. To observe the influence of the opening percentage on the solutions, the opening percentage $p$ is changed from $70 \%$ to $95 \%$, with an increment of $5 \% . R$ is set to be $2.5 \mathrm{~km}$. Figures $13(\mathrm{a})-13$ (c) show the results. The points marked by green (triangle) are stores selected to close, while those marked by red (square) are retained as open. As the value of $p$ is changed from $70 \%$ to $95 \%$, more stores located in the suburbs are selected for 

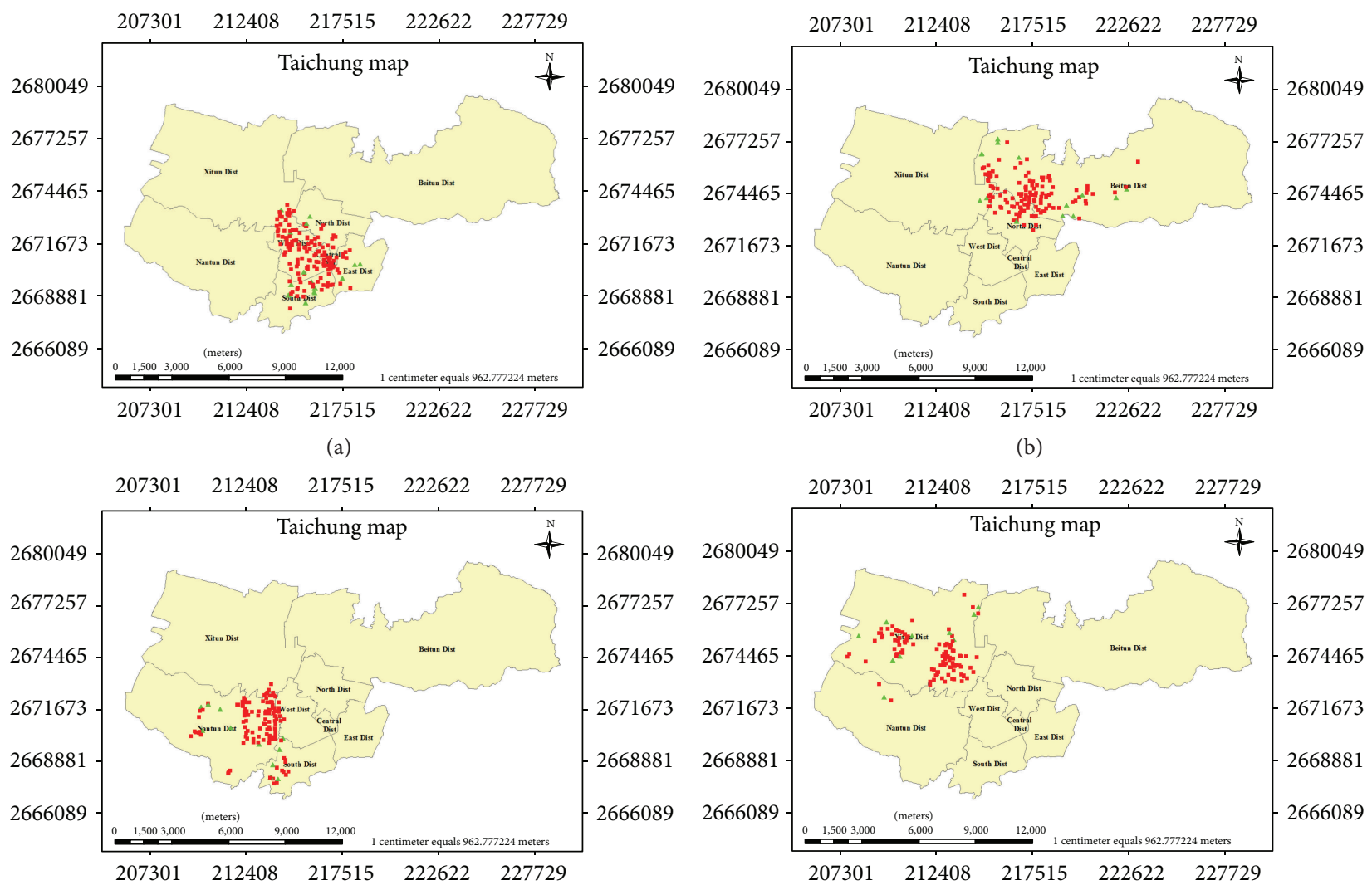

(c)

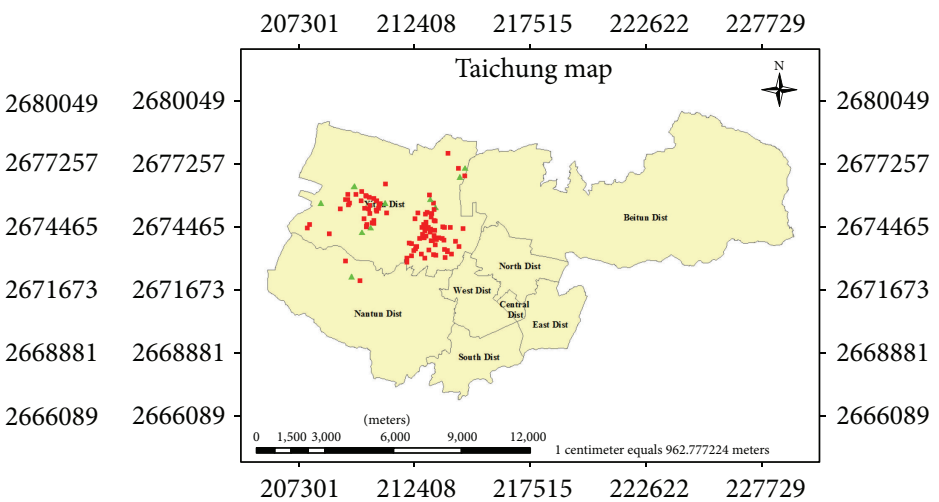

(d)

FIgURE 11: (a) The store selection results for cluster 1. (b) The store selection results for cluster 2. (c) The store selection results for cluster 3. (d) The store selection results for cluster 4 .

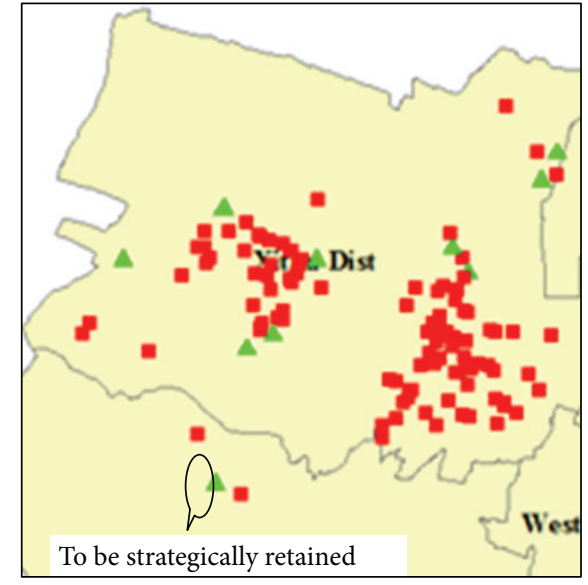

(a)

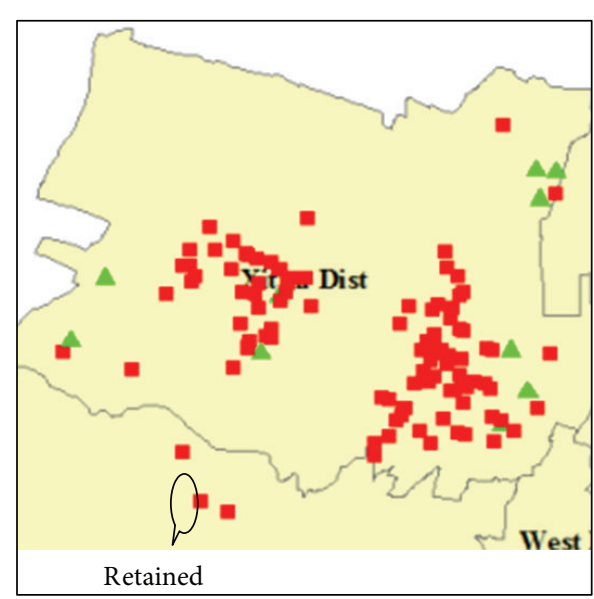

(b)

FIGURE 12: The result and its influence for a strategically retained store.

closure. The reason is that the revenue of the stores located in the suburbs is generally less than the revenue of those located in the city center.

To facilitate the observation of results, the Pareto solutions are presented in Figure 14. As the total movement distance increases, the total profit loss decreases. Figure 14 shows this trend. As expected, a higher value of $p$ has a lower profit loss.

4.4. The Influence of Neighborhood Radius. The neighborhood radius $R$ is varied from $1 \mathrm{~km}$ to $3 \mathrm{~km}$, with an increment of $1 \mathrm{~km}$ to see its influence on the results. The selected 


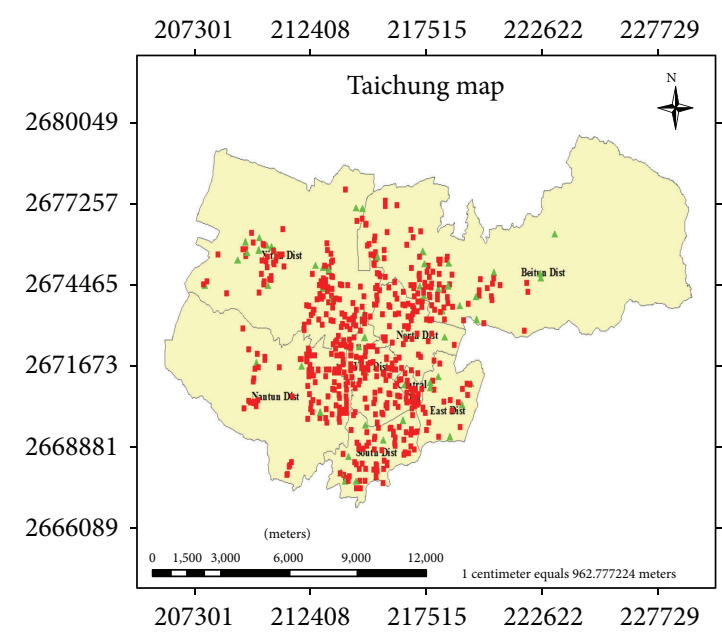

(a)

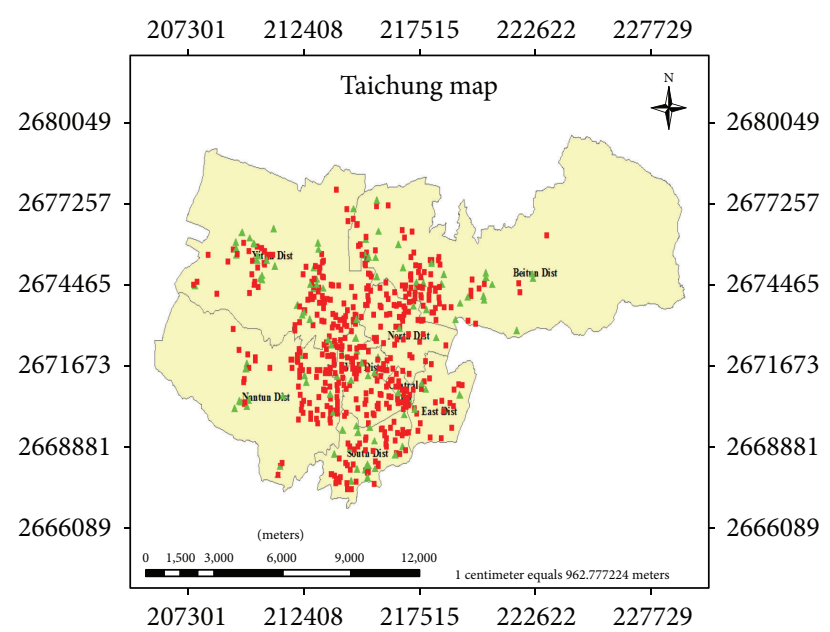

(b)

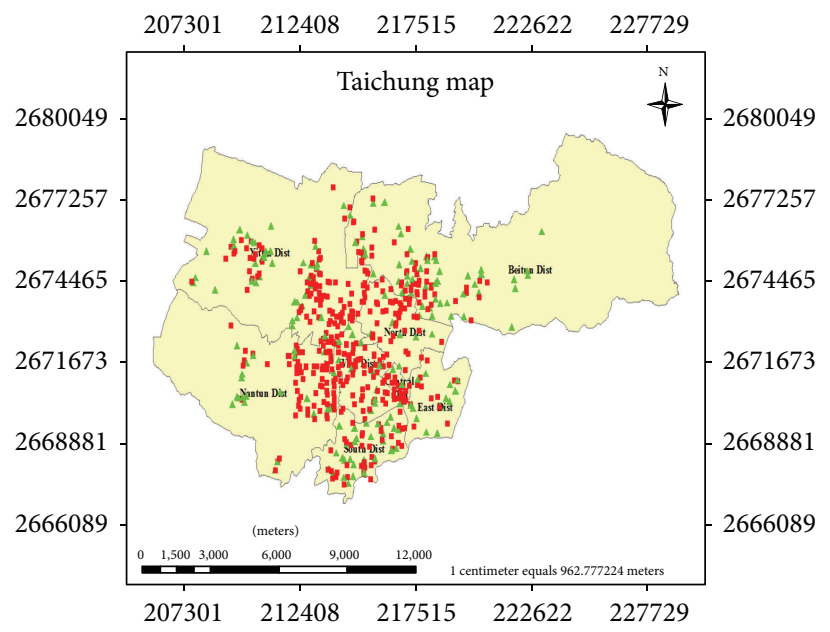

(c)

Figure 13: (a) The results for opening percentage $p=90 \%$. (b) The results for opening percentage $p=80 \%$. (c) The results for opening percentage $p=70 \%$.

locations where stores are to close are marked with a green triangle. As $R$ is increased, the selected stores gradually move from the city center to the suburbs, as we can see from Figures 15(a)-15(c). This is an important finding that would help managers make the right decisions. Using the system developed in this paper, the managers can easily simulate and may effectively control their profit loss if stores are to close.

The variation of the total profit loss with the total movement distance is shown in Figure 16. As the total profit loss decreases, the total movement distance tends to increase.

Special note must be taken that a higher value of $R$ may cause more lost customers, which, in turn, causes more lost profit. A previous survey [11] shows that when the distance increases, the percentage of willingness to walk to buy decreases, as displayed in Figure 17. When the distance is longer than $150 \mathrm{~m}$, more than $20 \%$ of people are possibly not willing to walk to another store [11].

4.5. The Influence of Store Number. To investigate the influence of the number of stores on the performance of the
GA program, a lot of experiments with different numbers of stores are performed. The number of stores is changed from 200 to 1,500. The results are shown in Table 2 and Figure 18. The experimental results are based on 10 trials. As the number of stores increases, the average computation time increases in a linear manner, indicating that the GA program is timeefficient. In addition, the coefficient of variation $\left(C_{v}\right)$ is small, showing that the GA program is quite stable.

\section{Conclusions}

Retail store operators are facing intense pressure. As competitors flood the marketplace, operating profit is significantly reduced. Given such a circumstance, store operators have to think about closing some underperforming stores. In this paper, we propose a system based on a three-phase decision framework to address this issue. In the first phase, $k$-means algorithm and geographic information system (GIS) are first used to divide the stores into some regions. In the second phase, some stores can be strategically retained based on the 


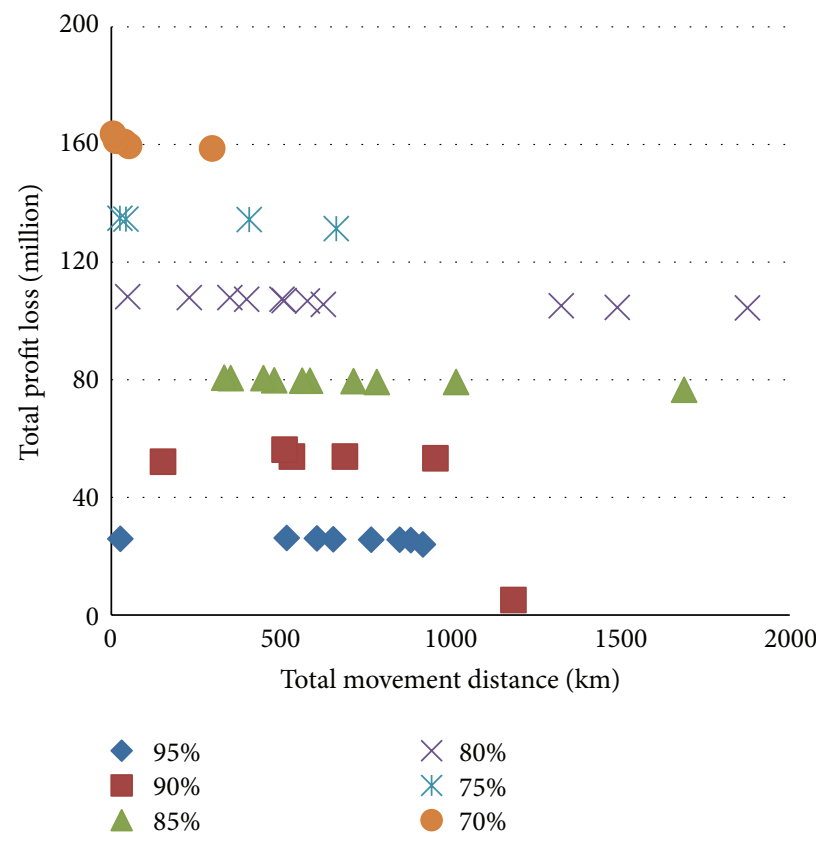

FIGURE 14: The variation of profit loss with total movement for different opening percentage.

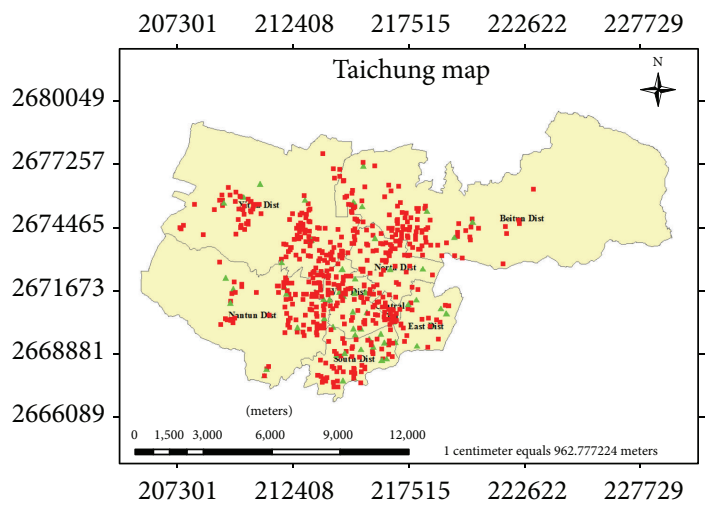

(a)

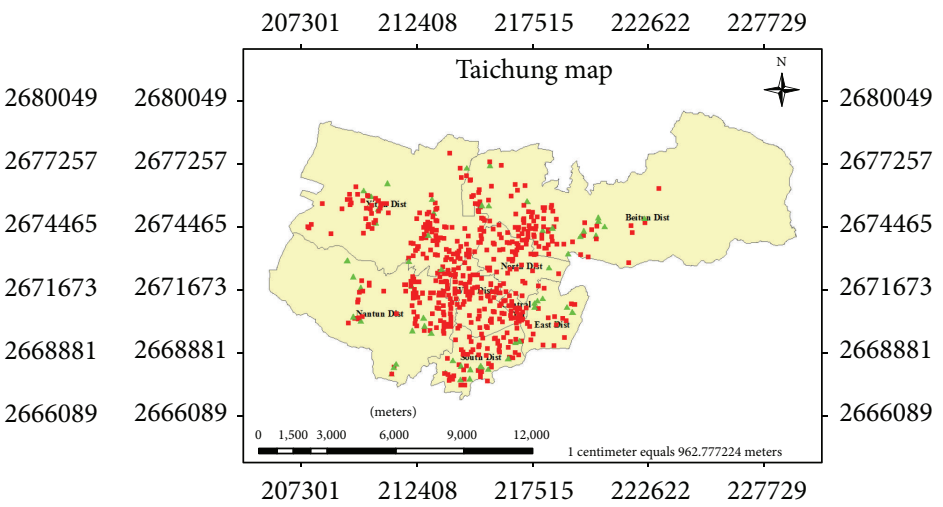

(b)

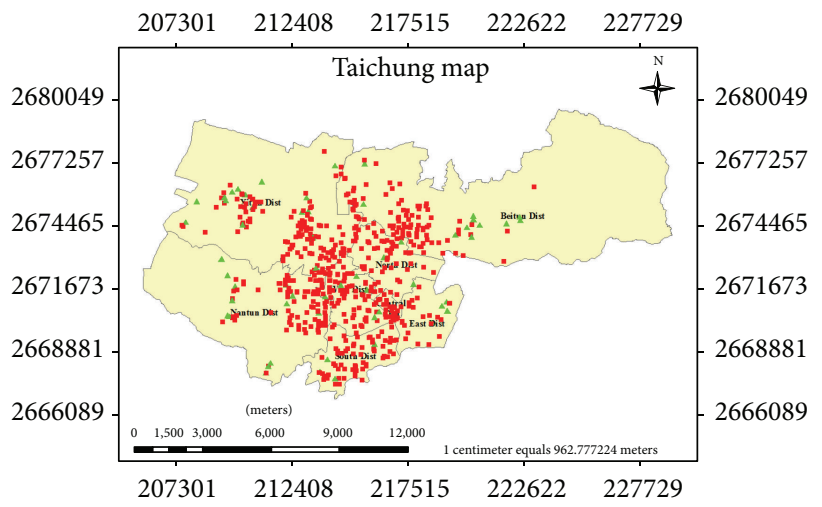

(c)

FIGURE 15: (a) The results for neighborhood radius $R=1 \mathrm{~km}$. (b) The results for neighborhood radius $R=2 \mathrm{~km}$. (c) The results for neighborhood radius $R=3 \mathrm{~km}$. 


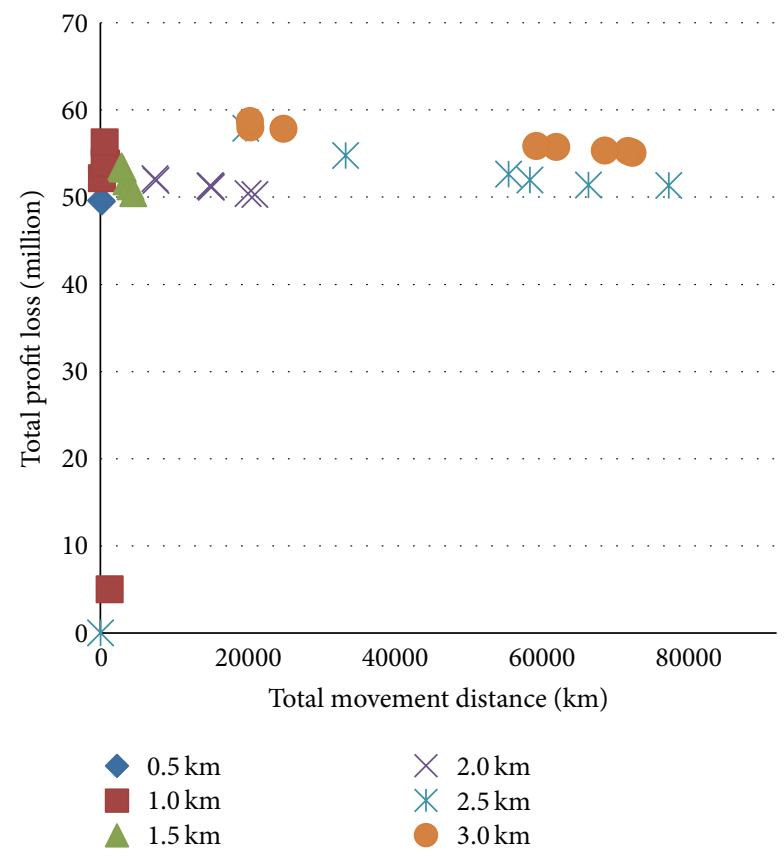

FIGURE 16: The variation of total profit loss with total movement distance for different neighborhood radius $R$.

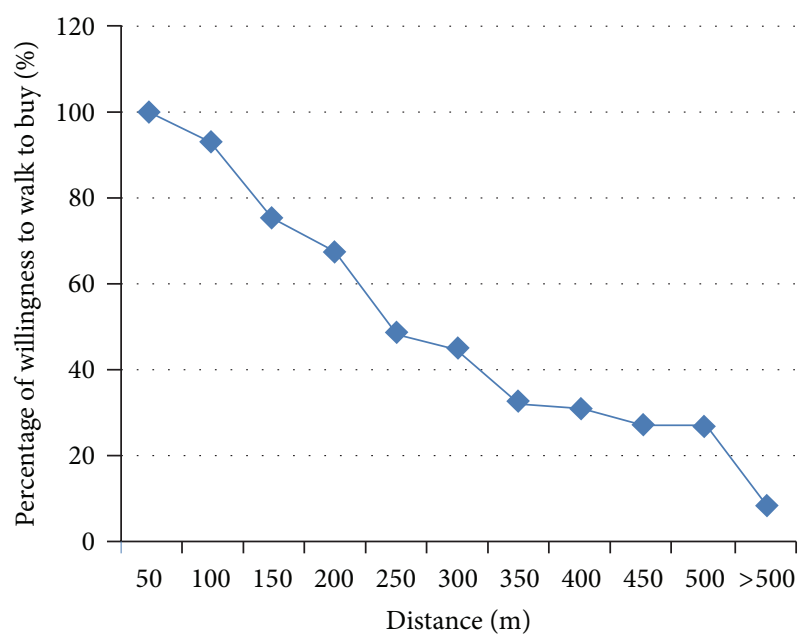

FIGURE 17: The variation of percentage of willingness to walk to buy with distance [11].

requirements of the company. Then, a new neighborhoodbased multiobjective genetic algorithm is employed to decide which stores are to close. To examine the effectiveness of the proposed framework, some real data provided by a stock-list company are used to execute some experiments. To investigate the influence of the number of stores on the performance of the GA program, a lot of experiments with different numbers of stores are performed. The experimental results are based on 10 trials.

Results from this study show that the proposed system can help decide store locations efficiently. As the number of stores increases, the average computation time increases in
TABLE 2: The variation of average (AVG) computation time with the number of stores.

\begin{tabular}{lccccccc}
\hline $\begin{array}{l}\text { Number } \\
\text { of stores }\end{array}$ & 200 & 400 & 600 & 800 & 1000 & 1200 & 1500 \\
\hline AVG & 1.550 & 3.042 & 4.115 & 5.351 & 6.575 & 7.588 & 9.620 \\
$C_{v}$ & 0.0158 & 0.0190 & 0.0104 & 0.0166 & 0.0106 & 0.0133 & 0.0185 \\
\hline
\end{tabular}

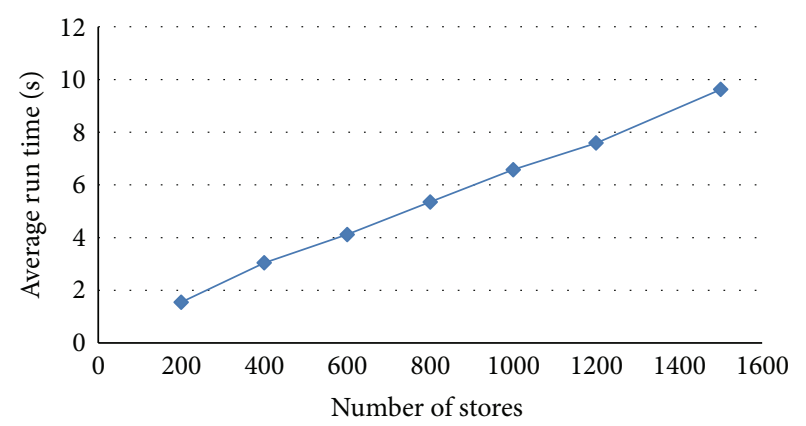

FIGURE 18: The variation of the average computation time with different numbers of stores.

a linear manner, indicating that the GA program is timeefficient. Moreover, the coefficient of variation is small, showing that the GA program is quite stable. As neighborhood radius is increased, the stores selected for closure gradually move from the city center to the suburbs. Special note must be taken that a higher value of neighborhood radius could cause more lost customers, since people are generally not willing to walk too far to find an alternative store when a store is closed.

A two-step approach, with clustering first and performing GA next, may result in suboptimal solutions. To get optimal solutions, integrated approaches are encouraged to be employed in the future. In this study, the interaction between different store chains is ignored. More studies are also needed to discuss the interaction between them and even collaboration with each other.

\section{Nomenclature}

\section{Superscripts}

$t$ : $t$ th generation.

\section{Subscripts}

0 : Original

$h$ : $h$ th individual, see (6)

$i$ : $i$ th retail store

$j: \quad j$ th nearby store of a selected (to-close) store

$n:$ The $n$th cluster

$C_{i}$ : The cost of store $i$

$d_{i j}$ : The distance from store $i$ to its $j$ th nearby store

$G_{h}$ : The $h$ th individual chromosome, see (6)

$k$ : The number of clusters

$K$ : Set of clusters 
$N_{i j}:$ The $j$ th nearby store of store $i$

$p:$ The percentage of stores that have to keep open

$q_{h}^{(t)}$ : The number of individuals that dominate the $h$ th individual at the $t$ th generation, (6)

$R:$ The neighborhood radius (see Figure 1)

$s_{0}$ : The total number of stores before strategic selection

$s_{n}$ : The number of stores after strategic selection for the $n$th cluster

$S$ : A set of retail stores

$V_{i}$ : The revenue of store $i$

$x_{i}$ : Decision variable: if store $i$ is to close, then $x_{i}=0$; otherwise, $x_{i}=1$

$Z_{1}$ : Objective 1: minimizing the total profit loss

$Z_{2}$ : Objective 2 : minimizing the total travel distance caused by store closure.

\section{Competing Interests}

The authors declare that they have no competing interests.

\section{Acknowledgments}

The authors wish to express their appreciation to Nancy D. Wall, Chih-Chiang Lin, Mei-Hui Wu, Mei-Chun Chen, ShaoWen Lien, Yi-Chen Tsai, Nuo-Jhen Ma, and Ya-Chu Chuang for their help during the course of this paper. This work was supported by the National Science Council under Grants nos. NSC 102-2221-E-025-013 and NSC 99-2815-C-025-007-E.

\section{References}

[1] A. M. Viswambharan and T. P. Vijumon, "Private super markets and margin free markets in Kerala: a comparative study of factors influencing consumers," Commerce Spectrum, vol. 2, no. 1, pp. 8-23, 2014.

[2] K. R. Manikyam, "Customers' relationship experience in small scale retail stores-a case Study," Sumedha Journal of Management, vol. 3, no. 2, pp. 66-79, 2014.

[3] H. Haans and E. Gijsbrechts, "Sales drops from closing shops: assessing the impact of store outlet closures on retail chain revenue," Journal of Marketing Research, vol. 47, no. 6, pp. 10251040, 2010.

[4] B. Y. Shih and Y. S. Chung, "The development of a CFM hybrid artificial sale forecasting model," International Journal of Electronic Business Management, vol. 6, no. 4, pp. 227-236, 2008.

[5] D. C. Jaravaza and P. Chitando, "The role of store location in influencing customers' store choice," Journal of Emerging Trends in Economics and Management Sciences, vol. 4, no. 3, pp. 302307, 2013.

[6] T. L. Saaty and M. P. Niemira, "A framework for making a better decision," Research Review, vol. 13, no. 1, pp. 1-4, 2006.

[7] E. Koç and H. A. Burhan, "An Application of Analytic Hierarchy Process (AHP) in a real world problem of store location selection," Advances in Management and Applied Economics, vol. 5, no. 1, pp. 41-50, 2015.

[8] E. Arrigo, "The role of the flagship store location in luxury branding. An international exploratory study," International
Journal of Retail \& Distribution Management, vol. 43, no. 6, pp. 518-537, 2015.

[9] F.-F. Wang, L.-F. Chen, and C.-T. Su, "Location selection using fuzzy-connective-based aggregation networks: a case study of the food and beverage chain industry in Taiwan," Neural Computing and Applications, vol. 26, no. 1, pp. 161-170, 2015.

[10] H.-J. Chang, C.-M. Hsieh, and F.-M. Yang, "Acquiring an optimal retail chain location in China," in Proceedings of the 2nd International Conference on Information Science and Control Engineering (ICISCE '15), pp. 96-99, Shanghai, China, April 2015.

[11] R.-C. Chen, Y.-W. Hsu, Y.-H. Ye, and C.-W. Huang, "Prediction of convenience store location based on support vector machines," International Journal of Digital Content Technology and Its Applications, vol. 6, no. 16, pp. 248-255, 2012.

[12] N. Wrigley, Store Choice, Store Location and Market Analysis (Routledge Revivals), Routledge, New York, NY, USA, 2014.

[13] G. Turhan, M. Akalın, and C. Zehir, "Literature review on selection criteria of store location based on performance measures," Procedia-Social and Behavioral Sciences, vol. 99, pp. 391-402, 2013.

[14] J. A. Pope, W. R. Lane, and J. Stein, "A multiple-attribute decision model for retail store location," Southern Business Review, vol. 37, no. 2, p. 15, 2012.

[15] I. Onden, H. Tuzla, and S. Cobb, "Evaluation of retail store location alternatives for investment decisions using the delphi technique and geographic information systems," International Business: Research, Teaching and Practice, vol. 6, no. 2, pp. 6475, 2012.

[16] S. D. Jena, J. F. Cordeau, and B. Gendron, "Solving a dynamic facility location problem with partial closing and reopening," Computers \& Operations Research, vol. 67, pp. 143-154, 2012.

[17] R. Srinivasan, S. Sridhar, S. Narayanan, and D. Sihi, "Effects of opening and closing stores on chain retailer performance," Journal of Retailing, vol. 89, no. 2, pp. 126-139, 2013.

[18] M. Shields and M. Kures, "Black out of the blue light: an analysis of Kmart store closing decisions," Journal of Retailing and Consumer Services, vol. 14, no. 4, pp. 259-268, 2007.

[19] R.-C. Chen and T.-T. Hu, "A decision-making mechanism considering carbon footprint and cost to fulfil orders for multisite global companies," International Journal of Shipping and Transport Logistics, vol. 7, no. 3, pp. 295-318, 2015.

[20] S. Chopra and O. Meindl, Supply Chain Management: Strategy, Planning, and Operation, Prentice Hall, Upper Saddle River, NJ, USA, 2015.

[21] J. Rak, L. Jurikova, and D. Sevcik, "Mapping the risks by means of geographic information systems," International Journal of Mathematical Models and Methods in Applied Sciences, vol. 7, no. 3, pp. 257-264, 2013.

[22] J. Micael, A. C. Costa, P. Aguiar, A. Medeiros, and H. Calado, "Geographic information system in a multi-criteria tool for mariculture site selection," Coastal Management, vol. 43, no. 1, pp. 52-66, 2015.

[23] M. H. Dunham, Data Mining Introduction and Advanced Topics, Prentice Hall, 2003.

[24] J. A. Hartigan and M. A. Wong, "Algorithm AS 136: a k-means clustering algorithm," Applied Statistics, vol. 28, no. 1, pp. 100108, 1979.

[25] J.-P. Zhang, H.-Z. Cheng, S.-X. Tian, and D. Yan, "Aggregation modeling of large wind farms using an improved K-means algorithm," WSEAS Transactions on Systems, vol. 13, pp. 492502, 2014. 
[26] M. Mukherjee, R. Cuthbertson, and E. Howard, Eds., Retailing in Emerging Markets: A Policy and Strategy Perspective, Routledge, 2014.

[27] J. H. Holland, Adaptation in Natural and Artificial Systems, University of Michigan Press, Ann Arbor, Mich, USA, 1975.

[28] D. E. Goldberg, Genetic Algorithm in Search, Optimization, and Machine Learning, Addison-Wesley, Reading, Mass, USA, 1989.

[29] D. A. Coley, An Introduction to Genetic Algorithms for Scientists and Engineers, World Scientific Press, Singapore, 1999.

[30] M. Gen, R. Cheng, and L. Lin, Network Models and Optimization: Multi-Objective Genetic Algorithm Approach, Springer, London, UK, 2008.

[31] R.-C. Chen and P.-H. Hung, "Multiobjective order assignment optimization in a global multiple-factory environment," Mathematical Problems in Engineering, vol. 2014, Article ID 673209, 14 pages, 2014.

[32] S.-S. Li, R.-C. Chen, and C.-C. Lin, "A genetic algorithm-based decision support system for allocating international apparel demand," WSEAS Transactions on Information Science and Applications, vol. 3, no. 7, pp. 1294-1299, 2006.

[33] C. M. Fonseca and P. J. Fleming, "Genetic algorithms for multiobjective optimization: formulation, discussion and generalization," in Proceedings of the 5th International Conference on Genetic Algorithms, vol. 1, pp. 416-423, 1993.

[34] P. R. Harper, V. De Senna, I. T. Vieira, and A. K. Shahani, "A genetic algorithm for the project assignment problem," Computers and Operations Research, vol. 32, no. 5, pp. 1255-1265, 2005.

[35] L. Chen, T. Yu, and R. Chirkova, "Wavecluster with differential privacy," in Proceedings of the 24th ACM International on Conference on Information and Knowledge Management (CIKM '15), Melbourne, Australia, October 2015.

[36] https://www.cs.uic.edu/ wilkinson/Applets/cluster.html. 


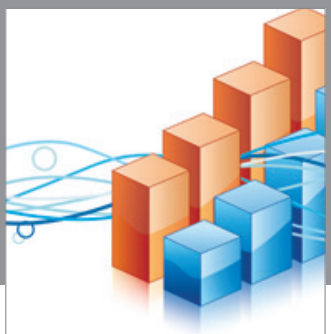

Advances in

Operations Research

vatem alat4

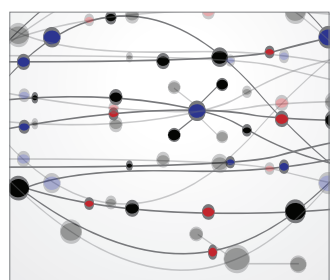

\section{The Scientific} World Journal
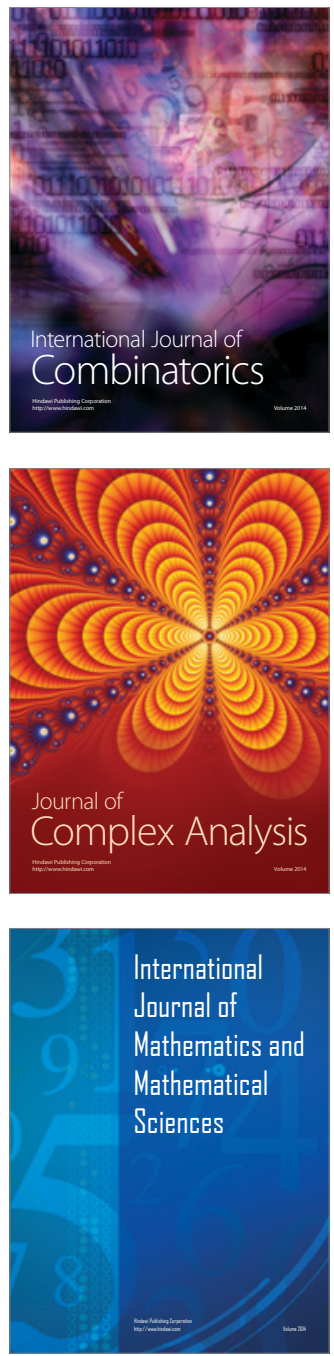
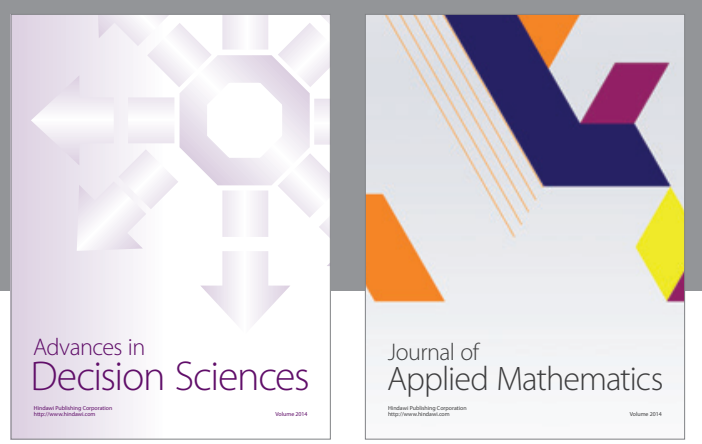

Algebra

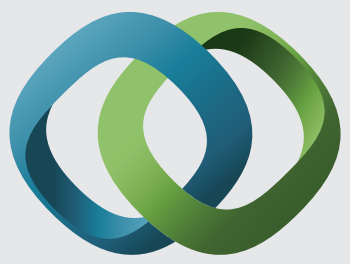

\section{Hindawi}

Submit your manuscripts at

http://www.hindawi.com
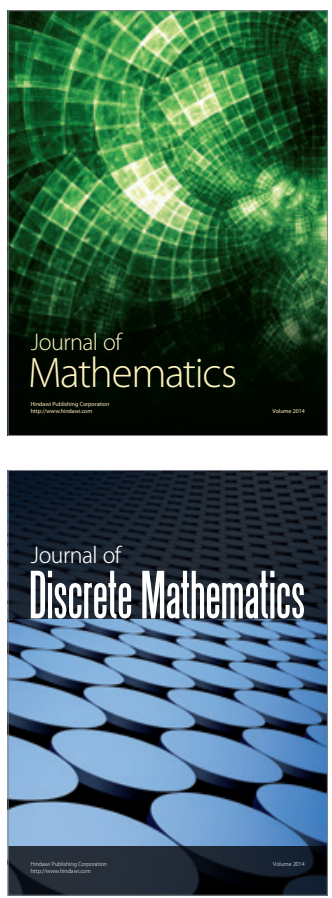

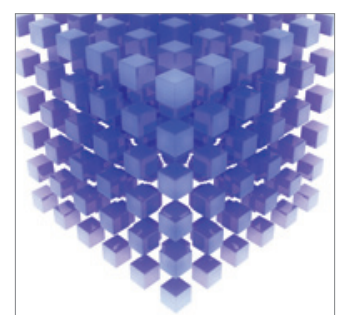

Mathematical Problems in Engineering
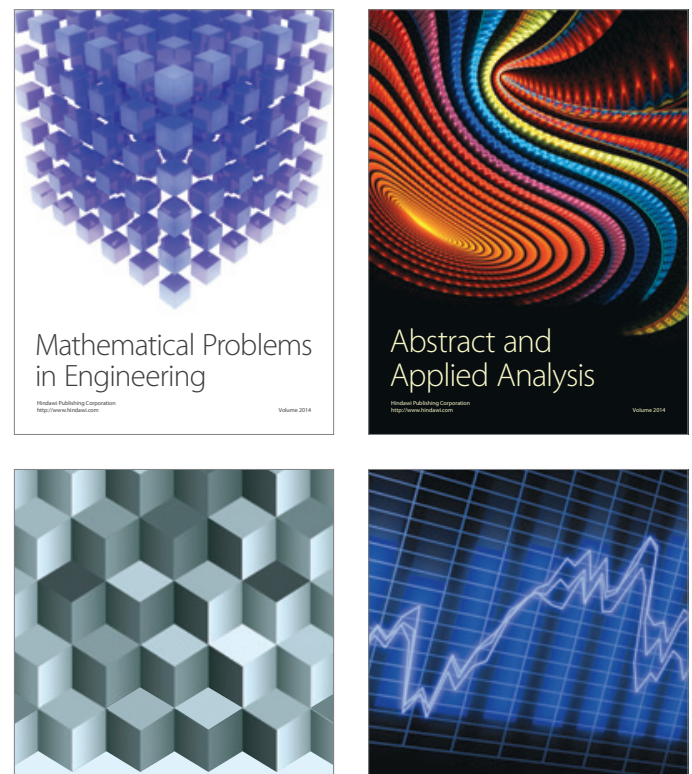

Journal of

Function Spaces

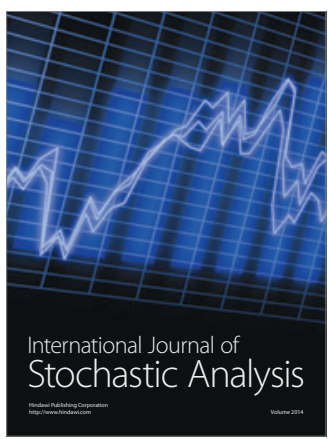

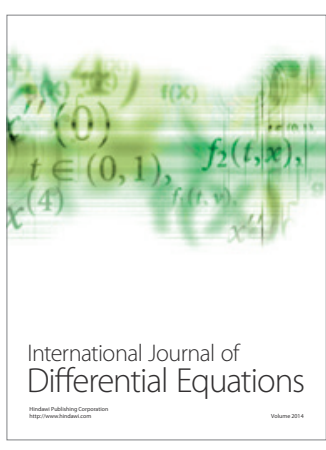
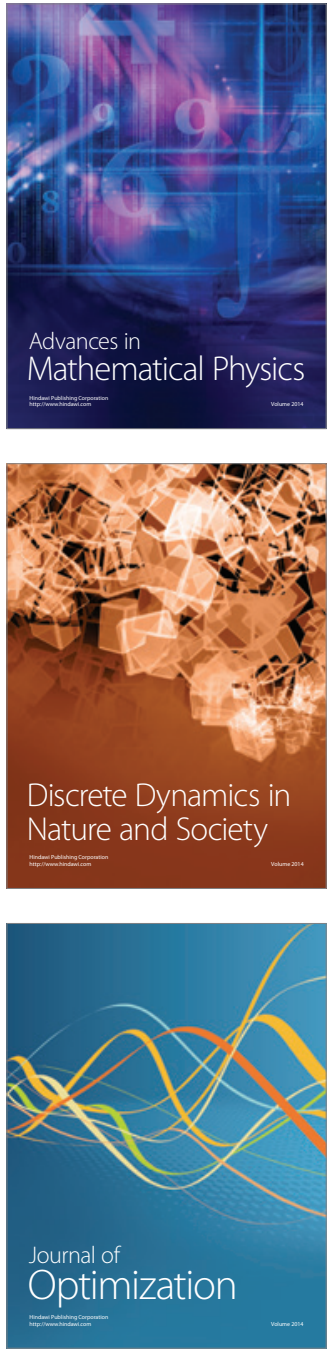